\title{
Precarização da Escola Pública e suas Implicações no Processo de Escolarização de Jovens de Camadas Populares: Um Relato de Jovens Estudantesda Escola Dr. Celso Malcher, Bairro da Terra Firme, Belém (PA)
}

Jesus de Nazaré de Lima Costa ${ }^{1}$ Maria José Aviz Rosário² Thaís Pimenta Pimentel ${ }^{3}$

\begin{abstract}
Resumo:
Neste artigo apresentam-se os dados relativos à pesquisa de campo realizada durante os estudos de mestrado pelo Programa de Pós-Graduação em Currículo e Gestão da Escola Básica/PPEB/UFPA, que teve como objetivo investigar sobre o processo de mobilização e luta dos jovens, pelo direito à educação, no seu itinerário de escolarização dos jovens da Escola Dr. Celso Malcher, entendendo este processo como paulatino na vida de cada sujeito, marcado por muitas idiossincrasias características peculiares de cada grupo conforme o espaço, o tempo e as condições dadas aos vários agentes. Durante a pesquisa, trabalhamos com duas categorias, escolhidas, a priori, a desigualdade e a contradição. o processo de escolarização dos jovens das camadas populares é marcado/permeado por grandes desafios, pois a garantia de uma escola e educação de qualidade para todos têm avançado muito lentamente no Brasil. As grandes desigualdades sociais existentes no Brasil são empecilho para a maioria dos jovens das camadas populares completarem o período de formação na escola básica. Este estudo ancora-se em autores como: Ribeiro, Lanes e Carrano, 2006; Dayrell, 2016; Abramo, 2014; Carrano e Dayrell, 2013. O estudo revelou que as categorias infraestrutura e trabalho influenciam bastante no processo de escolarização dos jovens, que culmina em mobilizações e participação dos jovens da escola em prol do direito a uma educação.
\end{abstract}

\section{Palavras-chave:}

Juventude. Escola. Processo de Escolarização. Precarização.

\footnotetext{
1 Mestre em Currículo da Escola Básica, Professor na Escola Nossa Senhora do Perpétuo Socorro II. E-mail: iesuscosta20@yahoo.com.br. ORCID iD: https://orcid.org/0000-0002-2571-9543.

2 Doutora em Educação, Professora da Universidade Federal do Pará. E-mail: mjoser0123@gmail.com. ORCID iD: https://orcid.org/0000-0001-8680-5181.

3 Especialista em Educação Étnico Racial, Professora da Secretaria Municipal de Educação de Ananindeua, Pará, Brasil. E-mail: thaispimenta10@hotmail.com. ORCID iD: https://orcid.org/0000-0002-4416-1661.
} 


\title{
Precarious Public School and its Implications in the Schooling Process of Young People from Grassroots Prosperity: A Report of Young Students from Dr. Celso Malcher School, Terra Firme neighborhood, Belém (PA)
}

\begin{abstract}
In this article we present the relative date to field research performed during the master's studies by the Postgraduate Program in Curriculum and Management of the Elementary School/PPEB/UFPA, with objective to investigate the process of mobilization and struggle of young people, for the right to education, in their schooling itinerary for the young people of the Dr. Celso Malcher School, understanding this process as gradual in the life of each person, evidenced by many idiosyncrasies specific to each group according to the space, time and conditions given to several individuals. During the research, worked with two categories, chosen, a priori, inequality and contradiction. The schooling process of young people from the grassroots prosperity is evidenced/permeated by great challenges, because the guarantee of a school and quality education for all has been advancing slowly in Brazil. The great social inequality in Brazil is an obstacle for the majority of young people from the lower classes to complete their studies in elementary school. This study is based on authors such as: Ribeiro, Lanes and Carrano, 2006; Dayrell, 2016; Abramo, 2014; Carrano and Dayrell, 2013. The study revealed that the infrastructure and work categories have great influence in the schooling process of young people, which culminates in the mobilization and participation of youths of school in favor of the right to the education.
\end{abstract}

Keywords: Youth. School. Schooling Process. Precariousness.

\section{Precarización de la escuela pública y sus implicaciones en el proceso de escolarización de jóvenes de estratos populares: un informe de jóvenes estudiantes de la escuela Dr. Celso Malcher, Barrio da Terra Firme, Belém (PA)}

\begin{abstract}
Resumen: Este artículo presenta datos relacionados con la investigación de campo realizada durante los estudios de maestría por el Programa de Posgrado en Currículo y Gestión de la Escuela Básica/PPEB/UFPA, que tuvo como objetivo investigar el proceso de movilización y lucha juvenil, por el derecho a la educación, en su Itinerario escolar de los jóvenes de la Escuela Dr. Celso Malcher, entendiendo este proceso como paulatino en la vida de cada sujeto, marcado por muchas idiosincrasias propias de cada grupo según el espacio, tiempo y condiciones dadas a los distintos agentes. Durante la investigación, trabajamos con dos categorías, elegidas, a priori, desigualdad y contradicción. El proceso de escolarización de los jóvenes de las clases bajas está marcado/permeado por grandes desafíos, ya que la garantía de una escuela y una educación de calidad para todos avanza muy lentamente en Brasil. Las grandes desigualdades sociales que existen en Brasil son un obstáculo para que la mayoría de los jóvenes de las clases bajas completen su período de formación en la escuela básica. Este estudio se basa en autores como: Ribeiro, Lanes Y Carrano, 2006; Dayrell; 2016; Abramo, 2014; Carrano y Dayrell, 2013. El estudio reveló que las categorías de infraestructura y trabajo influyen mucho en el proceso de escolarización de los jóvenes, que culmina en la movilización y participación de los jóvenes en la escuela a favor del derecho a la una educación.
\end{abstract}

Palabras clave: Juventudes. Escuela. Proceso de escolarización. Precarización. 


\section{Introdução}

Os estudos sobre a juventude brasileira, mais especificamente sua relação com a escola pública, no âmbito da educação têm cada vez mais ganhado espaço nas pesquisas acadêmicas, isso, de algum modo, se deve ao fato deste tema ser pertinente para compreender as diversas relações que permeiam o chão da escola e a vida dos jovens neste espaço denominado escola. O presente artigo tem como finalidade apresentar o resultado da pesquisa com os jovens do ensino médio da escola Dr. Celso Malcher, realizada no âmbito do mestrado acadêmico no Programa de Pós-graduação em Currículo e Gestão da Escola Básica - PPEB/UFPA. A pesquisa teve como objetivo analisar o processo de mobilização e luta dos jovens do ensino médio da Escola Dr. Celso Malcher pelo direito à educação de qualidade. Desse modo, nossa pesquisa tem como lócus a escola Dr. Celso Malcher, situada no bairro da Terra Firme, Belém, Pará.

\section{A Escola Dr. Celso Malcher e os Jovens}

Segundo o Projeto Político-Pedagógico (2005), a Escola Estadual de Ensino Fundamental e Médio Celso Malcher surge a partir da extinção de quatro outras escolas que funcionavam em Regime Comunitário - E.R.C. Amigos da Terra Firme; E.R.C. Padre Teodolino Novelo; E.R.C Povo Carente da Terra Firme e E.R.C Universal -, gerando a procura por vagas nas escolas do bairro, as quais não eram supridas pelas escolas já existentes, o que ocasionou necessidade de construção de uma nova escola, para atender esses educandos do bairro.

A partir dessa necessidade, inicia-se um processo de pressão por parte dos moradores, responsáveis, servidores da escola e dos estudantes destacando-se os jovens exigindo do Governo Estadual a construção de uma nova escola para atender aos alunos e funcionários das escolas extintas. Segundo o PPP de 2005, o lugar cedido para funcionar a escola foi um galpão locado pela SEDUC-PA, o qual seria reformado e transformado em salas de aulas. No início, a escola-galpão não tinha nome e o processo de matrícula era realizado pelos responsáveis no polo, e na ficha vinha escrito "Escola Nova". Segundo o PPP, em 21 de fevereiro de 2002, iniciou-se as aulas no galpão, pois a constante presença da mídia e pressão dos moradores fez com que o governo fizesse uma obra relâmpago para inaugurar a escola, contudo, não ocorreram adaptações necessárias para o funcionamento de uma escola naquele espaço, e sim, uma forma de silenciar a comunidade.

Segundo o PPP, o lugar escolhido como prédio que à época abrigou a escola foi simplesmente um galpão cedido para seu funcionamento, que hoje abriga o Posto de Identificação da Unidade Integrada Pro Paz (UIPP). Em 2014, começa uma articulação para a mudança para o anexo da Paróquia São Domingos de Gusmão, que fica localizada na Avenida Celso Malcher, por apresentar uma melhor estrutura se comparada ao Galpão. Essa movimentação começou com os próprios professores, alunos e responsáveis que começaram a fazer reuniões com a comunidade e com o próprio padre da igreja, pois até então era o único espaço disponível no bairro que apresentava uma condição boa para recebê-los. Assim, a escola permaneceu funcionando durante cinco anos no anexo da igreja. Porém, aquele ainda não era o prédio fixo da escola e não tinha condições de comportar a demanda que a escola exigia, além do espaço ser requisitado para outros fins, ou seja, ainda assim, a própria igreja usufruía do espaço.

O processo de mobilização dos educandos, professores, responsáveis e comunidade do entorno conseguiram com que a secretaria de educação providenciasse outro espaço para funcionar a escola e, em meados de 2013, a escola passou a funcionar no prédio que fica na subestação da Rede Celpa, no bairro da Terra Firme, onde funcionava a escola Nuremberg Borges, mantida pela Fundação Aquarela, que atendia crianças do bairro. Então a Secretaria de Educação Estadual fez a articulação com a rede Celpa e fechou contrato, onde até hoje, 2021, funciona a escola. 
Para pensar na escolarização, é preciso compreender suas demarcações e concepções: no desenvolvimento e nas ações oficiais que são mobilizadas, nos sujeitos que são escolarizados e no estudo realizado, que se trata especificamente dos estudantes do $3^{\circ}$ ano do ensino médio da Escola Dr. Celso Malcher. Para Rodrigues (2010, p. 26) "a escolarização é um processo que se desenvolve socialmente e de diferentes formas. Entretanto, torna-se um fenômeno digno de estudo, tanto quanto suas condições de emergência e seus sujeitos”. Depreende-se que a escolarização é um processo dinâmico que varia conforme o tempo e o espaço, no caso da escolarização formal tem uma relação direta com a escola.

Segundo Dayrell (2007, p. 1114), "o jovem constitui-se como um ator plural, produto de experiências de socialização em contextos sociais múltiplos, expressando os mais diferentes modos de ser jovem". Neste sentido, a juventude apresenta uma historicidade onde:

o sujeito é um ser humano aberto a um mundo que possui uma historicidade; é portador de desejos, e é movido por eles, além de estar em relação com outros seres humanos, eles também sujeitos. Ao mesmo tempo, o sujeito é um ser social, com uma determinada origem familiar, que ocupa um determinado lugar social e se encontra inserido em relações sociais. (CHARLOT, 2000, p. 31).

A compreensão e o sentido dados ao mundo, na perspectiva de Charlot (2000), são dados pelos sujeitos, uma vez que estes não estão no mundo de forma isolada e apática aos fenômenos culturais, políticos, sociais e econômicos. Os sujeitos acompanham as transformações na sociedade e nelas intervêm, ou seja, a história humana não é dada, e sim construída. Logo, o ser humano também não é algo dado, e sim construído, isto é, processo de transformação.

Para Charlot (2000), a constituição do ser se dá na medida em que se constitui como humano. Hannah Arendt, na obra A condição humana, pontua que:

A pluralidade humana, condição básica da ação e do discurso, tem o duplo aspecto de igualdade e diferença. Se não fossem iguais, os homens seriam incapazes de compreender-se entre si e aos seus ancestrais, ou de fazer planos para o futuro e prever as necessidades das gerações vindouras. Se não fossem diferentes, se cada ser humano não diferisse de todos os que existiram, existem ou virão a existir, os homens não precisariam do discurso e da ação para se fazerem entender. (ARENDT, 2010, p. 188).

Em Arendt, a condição humana é a pluralidade, ou seja, o homem é um sujeito de ação no mundo, na história, pois cada sujeito é um potencializador de transformação e mudança. Esse sujeito que não é algo dado e acabado tem a capacidade de agir, já que o sujeito vive numa constante relação humana, um com os outros, aqui e agora nas relações sociais.

No contexto contemporâneo, os jovens estão cada vez mais suscetíveis às diversas transformações. Muitas delas, ligadas ao advento da globalização, têm levado grandes mudanças em todas as sociedades. No cenário brasileiro, por exemplo, essas alterações têm levado ao aparecimento das violências urbanas, que têm marcado sistematicamente a condição juvenil no Brasil. Tais fatores se devem ao fato da juvenilização da criminalidade, principalmente dos jovens das camadas populares, estreitamente relacionado com a ampliação das fronteiras do mercado de drogas, assim como um maior controle do crime organizado nas comunidades populares. Segundo Peralva (1997, p. 23):

O novo significado dos estudos sobre juventude emerge ao que parece desse conjunto de transformações. Enquanto o adulto vive ainda sob o impacto de um modelo de sociedade que se decompõe, o jovem já vive em um mundo radicalmente novo, cujas categorias de inteligibilidade ele ajuda a construir. Interrogar essas categorias permite não somente uma melhor compreensão do universo de referências de um grupo etário particular, mas também da nova sociedade transformada pela mutação. 
Desse modo, tais questões que norteiam a vida dos jovens das comunidades populares têm contribuído para uma má compreensão dos jovens aqui em destaque, assim como para uma afirmação estereotipada desses sujeitos, que mesmo alijados por parte do Estado de direitos fundamentais, como educação de qualidade, saúde, espaços culturais de lazer etc., aprendem, compartilham e trocam conhecimentos a partir de sua realidade sobre os assuntos diversos; e ainda que exista uma "cartografia da violência urbana" que afeta diretamente esses sujeitos, os jovens são agentes de transformação.

Entretanto, segundo Arroyo (2011, p. 225):

[...] são os mesmos vistos como incômodo nas cidades, nas ruas, nas manifestações culturais, até nas famílias. São adolescentes e jovens objeto de reportagens negativas na mídia e das ocorrências policiais. [...] são os destinatários de programas de emprego que lhe abram alguma perspectiva de futuro. São outros porque sem futuro, sem lugar.

Esses vários outros são os diversos sujeitos que hoje adentram o espaço escolar: jovens homossexuais, negros, indígenas, pessoas com deficiência, renda per capita inferior a um salário mínimo etc., que por muito tempo ficaram fora do espaço escolar, por falta de políticas públicas que garantissem o acesso a este espaço de formação. No caso dos jovens, especificamente no contexto escolar, para Dayrell (2007, p. 3) há

um contingente de alunos cada vez mais heterogêneo, marcados pelo contexto de uma sociedade desigual, com altos índices de pobreza e violência, que delimitam os horizontes possíveis de ação dos jovens na sua relação com a escola.

Assim sendo, a escola ainda vive o dilema da adaptação aos novos sujeitos que hoje estão frequentando esse espaço.

A maioria dos jovens que hoje estão na escola pública brasileira, além de encontrar todos esses desafios já postos no seu processo de escolarização, ainda encontra a invisibilidade dos seus traços e suas potencialidades, pois ele é visto apenas na sua condição de aluno, ou seja, esse jovem é encoberto. Como muito bem escreveu o filósofo Latino, Dussel (1993) o "Encobrimento do Outro", esse encobrimento do outro é fruto de uma modernidade colonizadora onde:

O ego moderno apareceu em sua confrontação com o não-ego; os habitantes das novas terras descobertas não aparecem como Outros, e sim como o Mesmo a ser conquistado, colonizado, modernizado, civilizado, como "matéria" do ego moderno. E é assim como os europeus (ou os ingleses em particular) se transformaram [...] nos "missionários da civilização em todo o mundo", em especial com "os povos bárbaros". [A] Europa constituiu as outras culturas, mundos, pessoas como ob-jeto: como o "arrojado" (-jacere) "ante" (-ob) seus olhos. O "coberto" foi "descoberto": ego cogito cogitatum, europeizado, porém imediatamente "en-coberto" como Outro. (DUSSEL, 1993, p. 46).

Ao lançar mão desse pensamento Dusseniano, busca-se explicar como esses outros sujeitos que chegam à escola são vistos, ou seja, são pessoas que vão ainda ser moldadas, segundo uma lógica já estabelecida, uma vez que não se reconhece os jovens como sujeitos de cultura, como detentores de conhecimentos e experiências ricas de significados, eles são vistos como depositários de conhecimento/saber.

Nessa perspectiva, o outro é visto como culpado de sua própria condição de incapacidade, referendando a máxima "ele não se esforçou o suficiente". Assim sendo, aos jovens das comunidades populares é negado reconhecimento como outro, sua condição de sujeito sociocultural, pois estes jovens em maioria são vistos apenas como trabalhadores, filhos de trabalhadores, consumidores, negros etc. 
Assim, para Dayrell (2007), os estudos sobre a juventude e a escola, na maioria das vezes, inclina-se para uma visão apocalíptica, referente ao fracasso da instituição escolar entre seus pares, ainda destacando que:

para a escola e seus profissionais, o problema situa-se na juventude, no seu pretenso individualismo de caráter hedonista e irresponsável, dentre outros adjetivos, que estaria gerando um desinteresse pela educação escolar. Para os jovens, a escola se mostra distante dos seus interesses, reduzida a um cotidiano enfadonho, com professores que pouco acrescentam à sua formação, tornando-se cada vez mais uma 'obrigação' necessária, tendo em vista a necessidade dos diplomas. Parece que assistimos a uma crise da escola na sua relação com a juventude, com professores e jovens se perguntando a que ela se propõe. (DAYRELL, 2007, p. 1105).

Por esse ponto de vista, a conexão entre escola e juventude é um processo complexo e que o cerne problemático não é necessariamente voltado apenas às relações entre educando, professor e família. O debate vai além de tal relação, já que se faz necessário entender o contexto histórico, social, cultural e o que propõe a escola aos estudantes do Ensino Médio.

Ainda segundo Dayrell (2007), é preciso compreender as diferentes transformações pelas quais a juventude atual tem passado, isso revela que suas demandas e necessidades próprias precisam ser problematizadas para podermos entender as práticas simbólicas e suas manifestações juvenis.

No contexto educacional brasileiro ainda se tem vigente prática de pensar educação pautada na adequação dos jovens ao modelo educacional de acordo com a concepção dominante vigente. Entretanto, é preciso repensar esse modo de fazer educação. É preciso "uma mudança do eixo da reflexão, passando das instituições educativas para os sujeitos jovens, onde é a escola que tem de ser repensada para responder aos desafios que a juventude nos coloca" (DAYRELL, 2007, p. 1107).

Nesse caminho, autores como Ferrett, Zibas e Tartuce (2004) têm destacado que já existem documentos oficiais que explicitam a necessidade da valorização e participação dos jovens no cotidiano da escola, dentre os documentos, citamos as Diretrizes Curriculares Nacionais para o Ensino Médio - DCNEM, segundo os autores, constituem o meio legal mais importante para a difusão do protagonismo juvenil no ensino médio, pois é por meio dessa participação que as unidades escolares tornam sua gestão mais democrática e conseguem efetivar sua função, possibilitando, com isso, um espaço pedagógico mais atraente e provocador para os jovens, tendo em vista o desenvolvimento acadêmico, social e afetivo.

Tais questões levam a refletir sobre a importância de estudos que compreendam essa parcela da sociedade brasileira, no caso, aqui, a juventude da Escola Celso Malcher, localizada no bairro da Terra Firme.

Tomando como referência Frigotto (2004), afirma-se que a juventude aqui estudada tem rosto muito bem definido, pois são sujeitos que pertencem a uma divisão de classe ou fração de classe muito demarcada na sociedade brasileira, em razão de serem filhos e filhas de pessoa assalariadas, desempregadas, autônomas, que em muitos casos, vivem em situações precárias de vida, assim como aponta Frigotto (2004, p. 181):

Os jovens que nos referimos nesta análise têm 'rosto definido'. Pertencem a classe ou fração de classe de filhos de trabalhadores assalariados ou que produzem a vida de forma precária por conta própria, no campo ou na cidade, em regiões diversas e com particularidades sociocultural e étnicas. Compõe esse universo seus milhões de crianças e jovens que têm inserção precoce no mundo do emprego ou subemprego. Inserção que não é sua escolha, mas uma imposição de sua origem social e do tipo de sociedade que se construiu no Brasil.

Tem-se ao longo deste texto uma tentativa de demarcar estreita relação entre juventude e classe, uma vez que compreendemos que os jovens que vivem nas camadas populares, em muitos casos, são alijados de direitos fundamentais, como uma educação de qualidade, por exemplo. Por outro lado, 
conforme ponderamos, os jovens que residem nessas localidades são os que mais evadem e abandonam a escola básica, isso está muito relacionado à questão do trabalho e à mão de obra barata.

Compreende-se, assim, que na escolha entre ter que trabalhar e estudar, vence a lógica do trabalho, ou seja, uma lógica de mercado, empresarial, que vê nesses jovens a possibilidade de colocá-los em postos de trabalhos subalternizados, com pouca valorização e recompensa financeira.

A realidade dos dados supracitados mostra a contradição em relação ao Plano Nacional de Educação (2014-2024), pois pelo Plano, até 2016, o atendimento aos jovens na faixa etária entre 15 e 17 deveria ser universalizado, conforme contido na sua meta 3 "Universalizar, até 2016, o atendimento escolar para toda a população de 15 a 17 anos e elevar, até o final da década, a taxa líquida de matrículas no ensino médio para 85\%, nesta faixa etária” (BRASIL, 2014).

O grande número de jovens fora da escola é preocupante uma vez que estes, em muitos casos, vivem em situação de vulnerabilidade social. No texto que segue apontam-se com base nos dados obtidos nas entrevistas com os jovens estudantes do 3 o ano do ensino médio, alguns dos fatores que influenciam no seu processo de escolarização. Os dados que serão apresentados constam em forma de categorias, sendo o que os achados não são conclusivos, mas nos levam a refletir sobre a temática.

\section{Juventude e Infraestrutura Escolar}

Durante as entrevistas com os jovens, a categoria referente à precarização da escola, a qual evidencia a infraestrutura (ou a falta dela), apareceu constantemente nos dados levantados na pesquisa de campo. Essa categoria é fundamental relativa ao objeto de estudo, porque foi a partir dela que se iniciou o percurso das mobilizações por uma educação de qualidade, movida principalmente pelos jovens junto à comunidade escolar.

Uma categoria presente na fala dos jovens entrevistados diz respeito à infraestrutura, ou na palavra deles, estrutura. Essa categoria está relacionada às condições físicas e materiais do espaço escolar, segundo o Censo Escolar (INEP, 2017), quando se analisa a infraestrutura das escolas brasileiras leva-se em consideração a existência dos seguintes indicadores: local próprio de funcionamento da escola, água tratada, energia elétrica, saneamento básico, coleta de lixo, esgoto e presença de banheiro na escola, assim como biblioteca, laboratório, cantina, computadores e outros equipamentos eletrônicos. Quando perguntado sobre a Escola Dr. Celso Malcher, obteve-se as seguintes respostas:

Eu acho que ela precisa de mais estrutura, porque a estrutura do Celso Malcher hoje em dia está meio degradante, ela não tem uma estrutura própria. Ela está alugada aqui e por um tempo ela já foi alugada mais ali na frente, ela não tem uma estrutura própria. (Entrevistado 01, 2017).

Não sei, é difícil dizer! Eu não estou no Celso há muito tempo, então... mas, pelo pouco tempo que tô aqui, é uma escola que já evoluiu bastante desde o primeiro ano que eu entrei aqui, de lá pra cá a escola já evoluiu em questão de educação e questão de infraestrutura também. É uma escola que está passando por um processo meio difícil, mas está evoluindo. (Entrevistado 02, 2017).

Em relação ao prédio, já foi melhor um dia, pelo fato de ser uma escola que virou uma escola pública ficou meio bagunçado... meio não, totalmente bagunçado, porque não teve mais manutenção. Em relação aos professores, eles são muito eficientes. Essa escola é a melhor do bairro pelo fato de os professores serem muito dedicados aos alunos, botar mesmo no pé dos alunos, por mais que a gente às vezes não quer fazer as coisas que eles pedem, mas tem muito professor bom. (Entrevistado 03, 2017).

Quando eu estava na sétima série estava presente, corremos atrás para a mudança de um novo prédio. Esse prédio ainda também não é nosso, mas estamos ao caminho de um novo prédio. (Entrevistado 04, 2017). 
Como podemos perceber, nas falas dos entrevistados a questão da infraestrutura tem papel fundamental no seu processo de escolarização, pois como eles mesmos expõem, a infraestrutura é requisito para um ensino que corresponda às suas expectativas, enxergando-a como algo a ser melhorado, uma vez que segundo os alunos, o espaço apresenta problemas, tal qual a falta de manutenção e um prédio fixo. Uma questão levantada pelo entrevistado número 03 é a relação escola pública e privada, pois ainda que não seja o foco deste estudo, é preciso salientar que historicamente alguns acreditam que a escola privada é melhor que a pública, e isso se deve ao fato da precarização cada vez maior das escolas públicas.

Então, entendemos que as questões relacionadas à infraestrutura da escola têm relação direta com o desenvolvimento de aprendizagem do estudante, uma vez que a garantia de uma educação de qualidade não está relacionada apenas a professores em sala de aula, mas também às condições materiais ofertadas.

A falta de infraestrutura de uma escola, como no caso da Escola Dr. Celso Malcher, que implica na não existência de um prédio próprio, assim como na falta de água, iluminação, merenda, ar-condicionado etc., tem relação direta com a evasão escolar, o que afirma as informações utilizadas neste estudo, tais como as de Arroyo (1991); Silva Filho e Araújo (2017) e Dayrell (2007). É preciso pensar a questão da infraestrutura escolar como uma parte importante para o desenvolvimento dos educandos, tal como apontam Alves e Soares (2013, p. 54):

As condições de infraestrutura e de complexidade da escola - medidas com os dados do Censo Escolar - também guardam relação significativa com o Ideb. Para terem seu direito educacional atendido, os alunos que trazem menos de casa precisam de escolas com melhor infraestrutura e mais focadas em suas necessidades de aprendizado.

Os estudos de Alves e Soares (2013) reforçam os resultados dessa pesquisa, direcionados para a importância da infraestrutura escolar no bom desempenho e rendimento dos alunos. Por essa razão, é tão frequente na fala dos jovens entrevistados a categoria (infra) estrutura, uma vez que não é um fator isolado, mas sim algo intrinsicamente ligado à escola e à vida dos alunos que têm este espaço como uma referência de socialização e aprendizado.

Em outro relato de um dos jovens vê-se aflorada a relação aluno/escola:

Eu estudo no Celso Malcher desde que mudei para cá há seis anos, com treze anos de idade, comecei na sexta série. Eu sempre falo que o Celso Malcher faz parte da minha identidade, eu vim do interior para cá e o único colégio que eu estudei aqui e eu nunca senti vontade de sair desde que eu entrei. Então, eu sinto um pertencimento muito forte por ele, e, mesmo apesar de ele não ter um prédio dele mesmo, mas eu acho que aluno é isso, tá ali junto com a escola, direção e professores para ter um espaço, para ter um lugar melhor para os jovens. (Entrevistado 05, 2017).

Pode-se notar na fala do entrevistado que essa relação estabelecida entre os estudantes e a escola demonstra que a escola não é algo isolado da vida dos estudantes, conforme salientado neste texto, uma parte do dia desses alunos é vivida na escola, a sua formação como sujeitos dá-se nas diversas relações sociais ali vividas, assim como apontam Abramo (2008); Charlot (2000); Arendt (2010) e Dussel (1993), a constituição dos sujeitos está ligada há um tempo e um espaço, relacionado a uma historicidade. Pois, os sujeitos estão em constante relação uns com os outros e um dos espaços que possibilita uma parte dessa convivência é escola.

Também é perceptível no relato, a relação de identidade estabelecida com a escola, uma vez que a identidade não é algo fixo, mas sim construído nas várias formas de existência do ser humano; numa perspectiva moderna, a identidade é algo mutável, ou seja, está em constante mudança. 
Conforme mostramos na caracterização da escola, a luta por um prédio adequado dá-se desde a origem da escola, pois a não existência de um prédio fixo implica na não conservação de arquivos relacionados à vida dos alunos e da própria história da escola, como também a falta de outros espaços dentro dela, por exemplo, uma biblioteca:

Eu vi muitos projetos, mas era bem difícil. Por exemplo, a gente não tinha uma biblioteca, para se pegar um livro a gente tinha que falar com a Cris que levava a gente lá em cima em uma sala, a gente revirava as caixas e dizia 'vou levar esse', ela anotava. Isso desanimava bastantes porque não tinha aquela oportunidade de chegar em uma prateleira e olhar os livros que você quer levar, é difícil você pegar dentro de uma caixa, um local só poeira. (Aluna egressa, 2017).

Como podemos verificar no relato acima, a falta de infraestrutura implica no processo de leitura dos alunos em um espaço que não seja a sala de aula, pois é necessário possibilitar espaços adequados nos quais os jovens possam ter autonomia para escolher um livro e, assim, melhorar sua visão de mundo tornando-se agentes multiplicadores de conhecimentos, ou seja, a fala do entrevistado está em consonância com a afirmação de Andrade e Laros (2007, p. 35) "depois do controle do nível socioeconômico do aluno, variáveis referentes à infraestrutura e aos equipamentos escolares são preditoras de um bom desempenho dos alunos".

Como bem se sabe, o bom desempenho do estudante no seu processo de escolarização e acesso aos bens culturais produzidos por mulheres e homens ao longo de nossa história depende também da possibilidade de contato dos estudantes com esses conhecimentos elaborados, e a biblioteca é um dos espaços onde os discentes podem buscar esses saberes. Pode-se observar que os alunos quando não encontram esses espaços tendem a "desanimar".

Por esse viés, pode-se inferir que a infraestrutura escolar tende a influenciar de forma negativa ou positiva no desempenho do estudante, assim como na sua permanência na escola, pois fatores ligados à falta dessa categoria como conservação, existência de um prédio fixo, instalações adequadas, recursos didáticos, bibliotecas, quadra de esportes e salas adequadas podem ser fatores decisivos no processo de escolarização e na relação dos alunos com a escola:

Para a melhoria da escola, porque quando a gente chegou aqui, por exemplo, lá no último andar, uma das salas os fios estavam tudo para fora, não tinha ar condicionado, era muito calor. Merenda, por exemplo, não tinha. A água às vezes faltava e a gente era dispensado cedo. Por isso que nós participamos. Sempre tem uma consequência né? E a nossa consequência foi atrasar nossos estudos. (Entrevistado 06, 2017).

A narrativa acima reafirma o que aqui fora apresentado sobre a falta de infraestruturas necessárias em uma escola: retardo no desenvolvimento no processo de ensino e aprendizagem, desânimo dos estudantes, falta de interesse e evasão. O questionamento do entrevistado é pertinente e nos leva a refletir quais as consequências da falta de infraestrutura de uma escola na vida dos jovens, apontado neste estudo nos trabalhos Arroyo (2011); Dayrell, (2007); Frigotto (2004) e Ianni (1968).

Assim, os jovens da escola Celso Malcher têm rostos bem definidos, são filhos e filhas de trabalhadores. Sendo a infraestrutura de sua escola um dos fatores que implicou diretamente com o ensino e aprendizagem de seus educandos, tornando-se um desafio para seus educandos e educadores a efetivação da educação de qualidade, haja vista que seus espaços eram inadequados ou inexistentes, tais como: as salas de aula não permitiam aulas de qualidade pela questão da péssima acústica, calor, falta de mobiliário e espaço; a falta de uma quadra que permitisse desenvolver as atividades esportivas e pedagógicas; a inexistência de um laboratório não permitindo o uso das tecnologias educativas; a necessidade de uma biblioteca que permitisse o incentivo ao mundo da leitura e pesquisa, além dos problemas de encanamento e iluminação. A consequência ou fim de tudo isso é a produção de mão de obra barata para o mercado de trabalho1.

1 Foi possível constar na pesquisa alguns dos trabalhos realizados pelos jovens, sendo, pedreiro, feirante, serviços gerais, construção civil e marcenaria. 


\section{Trabalho e sua relação na vida do estudante}

A relação juventude e trabalho possui conexão direta, uma vez que a opção pelo trabalho é um dos fatores da evasão e abandono da escola básica, assim como o objetivo pelo qual muitos jovens frequentam a escola, pois acreditam que com melhores estudos terão mais possibilidades de conseguir melhor colocação no mercado de trabalho. Assim, a realidade entre trabalho e escola é uma premissa válida na vida dos jovens das comunidades populares, sua conciliação não é tarefa fácil.

Conforme pôde-se constatar na entrevista quando perguntado sobre como foi ser pai e fazer o ensino médio, um dos jovens assim relatou: "foi um pouco complicado. Um pouco não, bastante complicado, porque tem que cuidar do bebê, correr atrás de trabalho e estudar. Então, é cansativo até demais, não só para mim, mas para qualquer outra pessoa seria cansativo" (Entrevistado 07, 2017).

A fala do entrevistado número 07 traduz a realidade de boa parte dos jovens moradores de comunidades populares, que por se tornarem pais ainda na adolescência, precisam buscar meios para sustentar sua família e, com isso, é construído obstáculo para prosseguirem nos estudos com êxito.

Quando questionado sobre: você só estuda ou estuda e trabalha? O pontuado foi:

Eu estudo e de vez em quando faço algum trabalho, de vez em quando pego algum trabalho de ajudante de pedreiro. Minha vó e minha mãe ficam toda hora em cima me mandando estudar que se eu não estudar quem vai ser prejudicado vai ser eu no futuro, porque como hoje em dia o trabalho depende muito de estudo então tenho que estudar muito pra conseguir uma coisa boa futuramente. (Entrevistado 07, 2017).

Desse modo, ainda é possível constatar na fala do entrevistado uma segunda problemática, que é conseguir emprego sem terminar a educação básica e sem ter experiência, o que mostra a importância de se concluir os estudos e qualificar-se para almejar empregos menos degradantes.

De acordo com o observado nas entrevistas, a categoria trabalho aparece com frequência na fala do jovem com sentidos diversos. Alguns aspectos são importantes neste jovem de 19 anos: primeiro ele já é pai; segundo, para ajudar na casa tem de dividir o seu tempo entre o estudo e eventuais trabalhos como auxiliar de pedreiro; terceiro, ele estuda pelo fato de ver no estudo possibilidade de melhor colocação no mercado de trabalho; quarto, as condições de trabalho precarizado nas formas eventuais de atuação profissional (os conhecidos "bicos").

O relato do jovem inconscientemente, ou não, atrela-se às características do trabalho na juventude:

No Brasil, a relação dos jovens com o trabalho é marcada por muitas desigualdades, e o Ensino Médio parece ser um espaço significativo para evidenciar esse fenômeno. Para uns, o tempo no Ensino Médio é vivido como etapa de formação e preparação para o acesso à universidade, ficando o trabalho como um projeto para depois da conclusão do Ensino Superior. Porém, para a maior parte daqueles que tiveram acesso a esse nível de ensino nas duas últimas décadas, a realidade de trabalho, de bicos ou de um constante se virar para ganhar a vida combinam-se às suas vidas de estudantes. (CORROCHANO, 2014, p. 206).

Podemos perceber a partir da concepção do autor que a relação do jovem com o trabalho é uma relação de necessidade, pois é preciso trabalhar para suprir suas próprias carências, de sua família e de sua filha. O trabalho, que nem sempre reúne condições boas e com salário justo, é mais uma inevitabilidade devido às relações sociais, estabelecendo um vínculo trabalho-sobrevivência.

Nesta perspectiva, cabe salientar que:

tal quadro tem feito com que se retraia o mercado de trabalho para profissionais de nível médio, enquanto aumenta a demanda de jovens por emprego. Os dados mostram que, na última década, diminuiu muito o desemprego dos jovens no Brasil, mas, ainda assim, os jovens têm que enfrentar um sistema perverso de seleção com exigências mais elevadas de 
escolarização para o ingresso em qualquer ocupação, mesmo quando a função não necessita de um nível elevado de conhecimento. Naturalmente, esse processo não garante ao jovem com Ensino Médio e com cursos de aperfeiçoamento um melhor lugar no mercado de trabalho, mas reforça o discurso da importância da educação escolar. (KRAWCZYK, 2014, p. 91).

Nesse fragmento de Krawczyk, é possível verificar a estreita relação contida na fala do jovem entrevistado (número 07) com a difícil realidade que os jovens brasileiros se encontram para se inserirem no mercado de trabalho, ao mesmo tempo que compreende que a educação possibilitará maiores chances na concorrência por uma vaga.

Assim sendo, a relação do jovem de baixa renda com o mundo do trabalho é uma relação estabelecida muito cedo. Para Leão e Nonato (2014, p. 11-12),

o trabalho é uma experiência marcante na vida dos jovens brasileiros, pois envolve suas perspectivas de vida, no presente e no futuro. Para muitos, as primeiras experiências já ocorrem no início da adolescência. Para outros, mesmo que ainda não estejam inseridos no mercado de trabalho, $o$ desejo de trabalhar e a preocupação em relação ao futuro profissional já se manifestam de uma maneira muito forte. Para financiar o lazer e adquirir itens de consumo juvenis - roupas, tênis, CDs, eletrônicos etc. -, muitos jovens precisam trabalhar. Outra grande parte faz do trabalho sua condição para estudar ou até mesmo para ajudar nas despesas de casa.

Podemos analisar a partir do que expõem os autores, que a categoria trabalho na vida dos jovens de camadas populares acontece de várias formas, marcantes positiva ou negativamente, pois quando vemos um jovem que terminou o ensino médio e adentrou ao mercado de trabalho, certamente ao ser questionado, dirá que esse fato marcou positivamente sua vida. Entretanto, se formos comparar com a fala do jovem entrevistado certamente a análise será diferente.

Contudo, é preciso deixar claro que essa imbricação trabalho e escola ou trabalho e estudo é uma relação marcada por desigualdades, ou melhor, é fruto das desigualdades sociais existentes no modelo capitalista, conforme foi salientado no tópico juventude e classe. Acredita-se, ou ainda no campo das hipóteses, que o jovem que trabalha e estuda é o filho do trabalhador, proletariado, com condições de renda baixa. Assim, o jovem se vê levado a trabalhar por conta de condições materiais desiguais existentes na sociedade brasileira.

Veja-se o relato a seguir:

Porque eu queria dinheiro pra comprar as minhas coisas e quando eu queria sair eu tivesse, tipo sapato roupa pra mim não ficar só dependo dos meus pais. E, ajudar eles também. Eu trabalho e vejo que pra pessoa ser o que quiser se no futuro só vai conseguir por meio do estudo. E que no trabalho eu aprendo coisas e na escola também. O trabalho era uma forma de eu conseguir dinheiro pra mim não tá roubando traficando matando e a escola eu estava aprendendo coisa pra conseguir o algo no meu futuro. (Entrevistado 08, 2017).

Não foi difícil, agora tá sendo barra pela questão que tem que ir trabalhar de manhã e estudar a tarde. Meu horário é meio apertado. Isso é cansativo, prova disso é que estou de recuperação em Matemática. É difícil, bem difícil. Problema de chegar em casa 13h30, 14h, quase na hora de já tá na escola, não conseguir almoçar antes da escola, essas coisas todas. (Entrevistado 02, 2017).

$\mathrm{Na}$ fala dos entrevistados, verificam-se alguns aspectos importantes para entender essa lógica juventude e trabalho, na qual se pode inferir: primeiro, pelo trabalho o jovem está menos propenso à criminalidade; segundo, com uma certificação do ensino médio, a probabilidade de um emprego melhor se eleva; e terceiro, trabalhando é possível ajudar na casa com as despesas da família etc. Essa terceira afirmação está presente em quase todas as falas dos jovens entrevistados que trabalham, estando explícito que os jovens que trabalham são tanto do turno da noite, como da tarde. 
Notou-se, também, nesta pesquisa que os jovens que trabalham pouco participam das atividades culturais, artísticas ou outros movimentos/projetos da escola, como podemos observar nas seguintes falas: "Chego na escola só estudo, não gosto de participar de nada. E, venho pra feira trabalhar." (Entrevistado, 09, 2017); "Só ia nas reuniões assinava no baixo assinado porque eu estudo a noite e trabalho de dia ae não dava pra mim ir" (Entrevistado 08, 2017); "Não. Não tenho como participar porque estou ocupado correndo atrás de emprego que eu tenho uma filha para criar" (Entrevistado 07, 2017).

Logo, observa-se como essa categoria é necessária para pensar sobre o processo de escolarização dos jovens das camadas populares, pois é possível inferir que os jovens que estudam e trabalham têm mais dificuldades para permanecer e concluir o ensino médio em relação aos que só estudam. Visto que, na maioria dos casos, os estudantes/trabalhadores têm de dividir o seu tempo entre a escola e as atividades laborais, esses jovens, com muitas dificuldades, frequentam as aulas, chegam atrasados, cansados etc. A análise dessa categoria nos permite afirmar inicialmente que a relação trabalho e escola é um "gargalo" na vida desses jovens que têm que trabalhar/sobreviver.

Verifica-se, portanto, que para uma grande parcela dos jovens das camadas populares, onde os pais em sua maioria têm pouca escolaridade, o trabalho é uma realidade cotidiana tendo forte influência no processo de escolarização.

Assim, nas grandes massas periféricas,

Além dos jovens pobres se verem privados da materialidade do trabalho e do acesso às condições materiais para vivenciarem a sua condição juvenil, defrontam-se também com a desigualdade no acesso aos recursos para sua autorrealização. Surge, assim, uma nova desigualdade - marcada pela privação cultural e negação do acesso a experiências que possibilitam o autoconhecimento e a descoberta de seus potenciais. Retoma-se, aqui, a importância das políticas públicas para garantir a todos os jovens as possibilidades de vivenciarem a juventude como uma fase de direitos a fim de que possam construir identidades positivas e projetos que afirmem sua dignidade. (ARROYO, 2014, p. 180).

De acordo com o que se tem apontado neste estudo, as desigualdades sociais implicam no acesso e permanência desses jovens no ensino médio. O que, se por um lado, as condições de acesso não são fáceis, a permanência também é outro desafio, e isso implica dizer que os jovens das camadas populares, quando submetidos à escolha de ter de trabalhar ou estudar, acabam se privando dos acessos a bens culturais produzidos.

Podemos observar que se tende naturalizar o trabalho como algo necessário na vida desses jovens, as relações e os motivos são outros, isto é, ele é imposto aos jovens e eles o assimilam com uma alternativa de garantia futura. Acredita-se que pelo trabalho os seres humanos se fazem sujeitos, constroem história, formam-se e humanizam-se como pessoas, entretanto, as relações de trabalho no modelo capitalista desumanizam e os colocam num sistema desigual e injusto, pois são obrigados a incorporar em nossas relações a lógica do mérito.

Assevera Arroyo (2014, p. 181) que:

os subalternizados não apenas estiveram e estão ausentes nos padrões de poder, de justiça, de propriedade da terra, do solo, da renda, do trabalho; estiveram e estão ausentes do padrão de conhecimento, de ciência. Ausentes no pensamento sociológico e pedagógico. Ausentes no conhecimento curricular.

As relações sociais têm sido demarcadas pelas posições que os sujeitos ocupam na sociedade e pela divisão social do trabalho, como mostramos na seção juventude e classe, é impossível pensar a juventude brasileira sem esse recorte de classe, pois, como mostrado, uns são pensados e formados para os melhores postos de comando, e outros, para os postos inferiores e subalternizados nas relações 
de trabalho. Destarte, a lógica do trabalho aparece na vida dos jovens seja como horizonte futuro ou como realidade já dada, o lugar que o trabalho ocupa na vida desses jovens está para além de uma opção de vida, ou consenso sobre os fundamentos que o norteiam.

Deste modo, a categoria trabalho nessa pesquisa revelou-se como um fator indireto que também influenciou no processo de luta e mobilização dos jovens do ensino médio por uma educação de qualidade na escola, pois os jovens entrevistados mostraram-se perceptíveis sobre a importância da educação em suas vidas como possibilidade de crescimentos, sendo a escola o lugar propício para o processo de educação acontecer de fato. Com isso, lutando por meios das mobilizações para a garantia, não apenas de um espaço fixo para a escola, mas também com condições estruturais e pedagógicas.

Entende-se que o debate sobre o processo de escolarização dos jovens de camadas populares não se esgota aqui, tampouco o processo de escolarização dos jovens estudantes do terceiro ano do ensino médio da Escola Dr. Celso Malcher. Essa temática é viva e atual em qualquer contexto.

Refletir tais questões sempre será necessário. Ou pelos menos enquanto houver exclusões sociais, desigualdades e desrespeitos aos direitos fundamentais dos jovens. Educação, lazer, segurança, saneamento, condições dignas para viver e concluir os estudos na educação básica de forma satisfatória, condições de prosseguirem os estudos no nível superior - se for o desejo destes sujeitos - jamais podem figurar fora dos anseios das juventudes. Construir estratégias de enfrentamento e de resistências frente às barreiras resultantes da falta de políticas públicas voltadas aos espaços pesquisados faz parte das constituições de seus atores, e a isso, rendemos louvores.

\section{Referências}

ALVES, Maria Teresa Gonzaga; SOARES José Francisco. Contexto escolar e indicadores educacionais: condições desiguais para a efetivação de uma política de avaliação educacional. Educação e Pesquisa, São Paulo, v. 39, n. 1, p. 177-194, jan./mar. 2013. Disponível em: http://www.scielo.br/pdf/ep/v39n1/v39n1a12.pdf. Acesso em: 25 mar. 2017.

ANDRADE, Josemberg Moura de; LAROS, Jacob Arie. Fatores associados ao desempenho escolar: estudo multinível com dados do SAEB/2001. Psicologia: teoria e pesquisa, Brasília, DF, v. 23, n. 1, p. 33-42, 2007. Disponível em: http:// www.scielo.br/pdf/ptp/v23n1/a05v23n1.pdf. Acesso em: 05 nov. 2017.

ARENDT, Hannah. A Condição Humana. Tradução de Roberto Raposo. Revisão técnica: Adriano Correia. 8. ed. Rio de Janeiro: Forense Universitária, 2010.

ARROYO, Miguel Gonzáles. Currículo, território em disputa. Petrópolis: Vozes, 2011.

ARROYO, Miguel Gonzáles. Os jovens, seu direito a se saber e o currículo. In: DAYRELL, Juarez; CARRANO, Paulo; MAIA, Carla Linhares (org.). Juventude e ensino médio: sujeitos e currículos em diálogo. Belo Horizonte: Editora UFMG, 2014. p. 157-188.

ARROYO, Miguel Gonzáles. Educação e exclusão da cidadania. In: BUFFA, Ester. Educação e cidadania: quem educa o cidadão. 4. ed. São Paulo: Cortez, 1991. p. 21-80.

BRASIL. Plano Nacional de Educação 2014-2024 [recurso eletrônico]: Lei n. ${ }^{\circ}$ 13.005, de 25 de junho de 2014, que aprova o Plano Nacional de Educação (PNE) e dá outras providências. Brasília, DF: Câmara dos Deputados, Edições Câmara, 2014. Disponível em: http://www.proec.ufpr.br/download/extensao/2016/creditacao/PNE\%202014-2024.pdf. Acesso em: 25 mar. 2017.

CHARLOT, Bernard. Da relação com o saber: elementos para uma teoria. Tradução Bruno Magne. Porto Alegre: Artes Médicas Sul, 2000.

CORROCHANO, Maria Carla. Jovens no Ensino Médio: qual o lugar do trabalho? In: DAYRELL, Juarez; CARRANO, Paulo; MAIA, Carla Linhares (org.). Juventude e ensino médio: sujeitos e currículos em diálogo. Belo Horizonte: Editora UFMG, 2014. p. 205-228. 
DAYRELL, Juarez Tarcísio. A escola faz as juventudes? Reflexões em torno da socialização juvenil. Educação e Sociedade, Campinas, v. 28, n. 100, p. 1105-1128, out. 2007.

DUSSEL, Enrique. O encobrimento do outro: 1492 a origem do mito da modernidade. Petrópolis: Vozes, 1993.

ESCOLA DR. CELSO MALCHER. Projeto Político Pedagógico (PPP). Belém: Escola Dr. Celso Malcher, 2005.

FERRETTI, Celso João; ZIBAS, Dagmar Maria Leopoldi; TARTUCE, Gisela Lobo Baptista Pereira. Protagonismo juvenil na literatura especializada e na reforma do ensino médio. Cadernos de Pesquisa. São Paulo, v. 34, n. 122, p. 411-423, maio/ago. 2004. Disponível em: http://dx.doi.org/10.1590/S0100-15742004000200007. Acesso em: 02 fev. 2018.

FRIGOTTO, Gaudêncio. Juventude, trabalho e educação no Brasil: perplexidade, desafios e perspectivas. In: NOVAES, Regina; VANNUCHI, Paulo (org.). Juventude e Sociedade: Trabalho, Educação, Cultura e Participação. São Paulo: Fundação Perseu Ramos, 2004. p. 180-216.

IANNI, Otávo. “O jovem radical”. In: BRITO, Sulamita (org.). Sociologia da Juventude, I da Europa de Marx à América Latina de Hoje. Rio de Janeiro: Zahar, 1968. p. 225-240.

INSTITUTO NACIONAL DE ESTUDOS E PESQUISAS EDUCACIONAIS ANÍSIO TEIXEIRA (INEP). Indicadores de Fluxo Escolar da Educação Básica. Brasília, DF: DEED/INEP, 2017.

LEÃO, Geraldo; NONATO, Symaira. Juventude e trabalho. In: CORREA, Licinia Maria; ALVES, Maria Zenaide; MAIA, Carla Linhares (org.). Cadernos temáticos: juventude brasileira e Ensino Médio. Belo Horizonte: Editora UFMG, 2014. p. 7-19.

KRAWCZYK, Nora. Uma roda de conversa sobre os desafios do Ensino Médio. In: DAYRELL, Juarez; CARRANO, Paulo; MAIA, Carla Linhares (org.). Juventude e ensino médio: sujeitos e currículos em diálogo. Belo Horizonte: Editora UFMG, 2014. p. 75-98.

PERALVA, Angelina Teixeira. O jovem como modelo cultural. Revista Brasileira de Educação, Rio de Janeiro, n. 5, maio/ago. 1997; n. 6, set./dez. 1997.

RODRIGUES, Maysa Gomes. Dos dizeres sobre a história, a infância e a escolarização: diálogos pertinentes. Paidéia: revista do curso de pedagogia da faculdade de Ciências Humanas, Sociais e da Saúde/FUMEC, Belo Horizonte, ano 7, n. 8, p. 11-40, jan./jun. 2010.

SILVA FILHO, Raimundo Barbosa; ARAÚJO, Ronaldo Marcos de Lima. Evasão e abandono escolar na educação básica no Brasil: fatores, causas e possíveis consequências. Revista Educação Por Escrito, Porto Alegre, v. 8, n. 1, p. 35-48, jan./jun. 2017.

Data de submissão: 30/01/2021

Data de aceite: 03/02/2021 